\title{
Conditional Risk Premia in International Government Bond Markets
}

\author{
Joëlle Miffre \\ EDHEC Business School, France
}

\begin{abstract}
The paper estimates conditional pricing models for 11 international government bonds and shows that, while local instruments capture the change in the bonds' risks, global instruments model the variation in the factor risk premia. Altogether the changes in the factor risk premium capture $78.25 \%$ of the bonds' predictability, while the dynamics in the betas account for less than $1 \%$. One cannot conclude however that the conditional models are well-specified as parameter instability and relatively large mean squared errors were uncovered. These results extend for the first time some of the evidence from the equity market of Ferson and Harvey (1993), Harvey (1995) and Ghysels (1998) to the bond market (JEL : G12, G15).
\end{abstract}

Keywords: international government bonds, conditional asset pricing models, variance ratio, mean squared errors, parameter stability.

\section{Introduction}

The predictability of returns is now one of the most accepted features of risky assets (Fama and French [1988, 1989]; Campbell and Shiller, [1988]; Campbell [1987]). It seems to prevail across asset classes and markets. For example, the phenomenon was identified in corporate bonds (Chang and Huang [1990]), in international government bonds (Ilmanen [1995]; Barr and Priestley [2004]), in developed equity markets (Ferson and Harvey [1993]; Zhang [2004]), in emerging equity markets (Harvey [1995]; Demos and Parissi [1998]) and in futures markets (Miffre [2000]). Most likely the predictability of returns reflects the fact that the premium required by investors as a compensation for risk and deferred consumption is time-dependent and fluctuates with the business cycle (Ferson and Harvey [1993]; Ferson and Korajczyk [1995]; Harvey

\footnotetext{
* The author would like to thank A. Clare, L. Kryzanowski and two anonymous referees for useful comments and suggestions. An earlier version of the paper was presented at the 2000 conference of the Multinational Finance Society.
}

(Multinational Finance Journal, 2008, vol. 12, no. 3/4, pp. 185-204)

Quarterly publication of the Multinational Finance Society, a nonprofit corporation.

(C) Global Business Publications. All rights reserved.

DOI: $10.17578 / 12-3 / 4-2$ 
[1995]). This suggests that the predictability of returns is consistent with rational pricing in efficient markets (Fama [1991]) and that asset pricing models that ignore this predictability may fail to give an accurate picture of the relation between an asset's risk and its expected return.

The time-variation in government bond returns has recently attracted some attention. Ilmanen (1995), for example, shows that a latent variable model with one time-varying factor risk premium and a constant beta captures the predictable movements in government bond returns. More recently, Barr and Priestley (2004) reinvestigated the issue of time-varying risk premia in government bond markets within a framework that (i) allows for partial market integration and (ii) models the change in the quantities of risk through an ARCH process. They found that international bond markets are to some extent segmented.

Like Ilmanen (1995) and Barr and Priestley (2004), this article confirms that the risk premia of 11 international government bonds fluctuate over time. ${ }^{1}$ The focus of this article is however different as we address the following three questions. It is worth noting that these questions have been investigated in international equity markets (Ferson and Harvey [1993]; Harvey [1995]; Ghysels [1998]) but the present paper is the first to study these topics for international government bonds:

1. Are the betas of international government bonds and the prices of systematic risk associated with a set of global risk factors time-dependent? We find that conditional models are well specified as local instruments capture the change in risks of international government bonds, while global instruments model the variation in the risk premia associated with the risk factors. This corroborates the evidence of Ferson and Harvey (1993) and Harvey (1995) from international equity markets.

2 . Is the predictability mainly driven by the changes in the factor risk premia or by the dynamics of the betas? Ferson and Harvey (1993) show that the variation in the prices of risk explains most of the predictability of international equity returns, leaving little variation to be explained by the conditional betas. We find that their inferences from international equity markets can be extended to international bond markets. Indeed the variations through time in the price of factor risk explain, on average, $78.25 \%$ of the predictability of international government bond returns while the conditional betas capture less than $1 \%$.

3. Are conditional asset pricing models better specified than static models when it comes to pricing international bonds? To tell the static

1. Despite this, financial analysts frequently use constant expected return asset pricing models as a way of measuring risk and estimating the return they should require for bearing that risk (Blake, Elton and Gruber [1993]; Elton, Gruber and Blake [1995]; Detzler [1999], for an analysis of the bond market). 
and conditional models apart, we compare their mean squared errors $(M S E)$ and find that the MSE of the static models are less than those of the conditional models. The tests also reveal that the parameters of the conditional models are unstable. This suggests that allowing for dynamics in the factor risk premia and in the betas might hurt more than it helps. This confirms the conclusions of Ghysels (1998) from the equity market.

The remainder of the article is organized as follows. Section II details the methodology employed to address the three research questions of the paper. Section III presents the dataset. Section IV discusses the empirical results. Finally section V concludes.

\section{Methodology}

\section{A. Are Factor Risk Premia and Measures of Risk Time-Dependent?}

To test for the presence of a time-varying risk premium in international government bonds, this paper uses a conditional model that allows for variation in the prices of risk associated with a set of systematic risk factors and for variation in the sensitivities of the bond returns to these factors. As Ferson and Harvey (1993) and Harvey (1995), we assume that a set of global instruments captures the variation through time in the prices of systematic risk and that a set of local instruments captures the change in the risk measures. In other words, the bond expected return $E\left(R_{t} \mid z_{t-1}^{G, L}\right)$ conditional on a set of global and local information $z_{t-1}^{G, L}$ is a function of the conditional prices of risk present in all asset markets $\left(F_{t}\right.$ $\left.z_{t-1}^{G}\right)$ and the conditional risk of the specific bond $\left(\beta_{t} \mid z_{t-1}^{L}\right)$. In mathematical terms, the bond conditional risk premium reads as follows:

$$
E\left(R_{t} \mid z_{t-1}^{G, L}\right)=\alpha+E\left[\sum_{j=1}^{K}\left(\beta_{j t} \mid z_{t-1}^{L}\right)\left(F_{j t} \mid z_{t-1}^{G}\right)\right],
$$

where $\alpha$ is a constant and $E\left(\cdot \mid z_{t-1}^{G, L}\right)$ is a conditional expectation on global $(G)$ and/or local $(L)$ information set and $K$ is the number of risk factors.

For each bond excess return, the following GMM model is estimated (Ferson and Harvey, [1993]):

$$
\begin{aligned}
& u 1_{t}=R_{t}-\left(\delta_{0}+\delta Z_{t-1}^{G, L}\right) \\
& u 2_{t}=F_{t}-\left(\gamma_{0}+\gamma Z_{t-1}^{G}\right)
\end{aligned}
$$




$$
\begin{aligned}
& u 3_{t}=\left(u 2_{t} u 2_{t}{ }^{\prime}\right)\left(\kappa_{0}+\kappa Z_{t-1}^{L}\right)-\left(u 2_{t} u 1_{t}\right) \\
& u 4_{t}=R_{t}-\alpha-\left(\kappa_{0}+\kappa Z_{t-1}^{L}\right)^{\prime}\left(\gamma_{0}+\gamma Z_{t-1}^{G}\right)
\end{aligned}
$$

$u 1_{t}, u 2_{t}, u 3_{t}$ and $u 4_{t}$ are error terms that are orthogonal to the instruments $z_{t-1}^{G, L}=\left\{1, Z_{t-1}^{G, L}\right\}, z_{t-1}^{G}=\left\{1, Z_{t-1}^{G}\right\}$ and $z_{t-1}^{L}=\left\{1, Z_{t-1}^{L}\right\} . Z_{t-1}^{G, L}, Z_{t-1}^{G}$ and $Z_{t-1}^{L}$ are, $(G+L-2) \times 1,(G-1) \times 1$ and $(L-1) \times 1$ vectors of mean zero global and/or local instruments; $R_{t}$ is the excess return on a government bond; $F_{t}$ is a $K \times 1$ vector of excess returns on mimicking portfolios $(K=1$ for the single index model and $K=6$ for the multi-factor model), where the portfolios mimic $K$ systematic risk factors. The parameters to estimate are $\left\{\delta_{0}, \delta, \gamma_{0}, \gamma, \kappa_{0}, \kappa, \alpha\right\}$, where $\delta$ is $1 \times(G+L-2), \gamma$ is $K \times(G-1), \kappa$ is $K \times(L$ $-1), \gamma_{0}$ and $\kappa_{0}$ are $(K \times 1), \delta_{0}$ and $\alpha$ are scalars.

The model implies the following orthogonality conditions:

$$
E\left(u 1_{t} z_{t-1}^{G, L}, u 2_{t} z_{t-1}^{G}{ }^{\prime}, u 3_{t} z_{t-1}^{L}{ }^{\prime}, u 4_{t}\right)=0
$$

for each bond excess return. System (1) is estimated via GMM (generalized method of moments). With $K$ risk factors, $G$ global instruments and $L$ local instruments, there are $(G+L)(K+1)$ orthogonality conditions and $(G+L)(K+1)$ parameters to estimate, leaving the model perfectly identified. As the result, there are no over-identifying restrictions to test.

The system of equations outlined in expression (1) assumes that the change in the sensitivities of bond returns to the risk factors, along with the shift in the factors risk premia, capture the time-varying risk premia present in international bond markets. (1a) uses both global and local instruments to capture the predictable change in bond returns. (1b) is a system of $K$ equations that defines the conditional factor risk premia as the fitted returns from a regression of the excess returns on the factor mimicking portfolios on the global instruments. (1c) determines the conditional betas $\left(\kappa_{0}+\kappa Z_{t-1}^{L}\right)$ as the conditional covariances $\left(u 2_{t} u 1_{t}\right)$ divided by the conditional variances $\left(u 2_{t} u 2_{t}^{\prime}\right)$. The conditional sensitivities $\left(\beta_{t} \mid z_{t-1}^{L}\right)$ are used along with the conditional factor risk premia $\left(F_{t} \mid z_{i-1}^{G}\right)$ to measure $\left(\kappa_{0}+\kappa Z_{t-1}^{L}\right)^{\prime}\left(\gamma_{0}+\gamma Z_{t-1}^{G}\right)$, the time-varying risk premium associated with each government bond in (1d). This equation defines $u 4_{t}$ as the residual from the conditional multifactor model with time-varying risks and prices of risk.

Within this framework it is easy to test for the presence of a time-varying risk premium in international government bonds. The bond 
will contain a time-varying risk premium if the coefficients on the lagged instruments are jointly significant; namely, if the risk and risk premia associated with some pre-specified risk factors change over time. For each of the risk factors separately, the paper tests for time-variation in the prices of factor risk $\left(H_{01}: \gamma=0\right)$ and for time-variation in the measures of risk $\left(H_{02}: \kappa=0\right)$. Finally the hypothesis $H_{03}: \gamma=\kappa=0$ is tested for all of the risk factors simultaneously. A rejection of $H_{03}$, when all factors are considered jointly, indicates the presence of a time-varying premium in the government bond under review and suggests that the data favors the conditional model over its unconditional counterpart.

B. Are the Variations in the Prices of Risk More Important than the Variations in the Betas at Explaining the Predictability of International Government Bonds?

Following Ferson and Harvey (1993) and Braun, Nelson and Sunier (1995) for the equity market, we test whether the predictability of international bond returns comes from time-variation in the prices of systematic risk or time-variation in the measures of risk. To test this, we estimate the following system of equations:

$$
\begin{gathered}
u 1_{t}=R_{t}-\left(\delta_{0}+\delta Z_{t-1}^{G, L}\right) \\
u 2_{t}=F_{t}-\left(\gamma_{0}+\gamma Z_{t-1}^{G}\right) \\
u 3_{t}=\left(u 2_{t} u 2_{t}{ }^{\prime}\right)\left(\kappa_{0}+\kappa Z_{t-1}^{L}\right)-\left(u 2_{t} u 1_{t}\right) \\
u 4_{t}=\left(\kappa_{0}+\kappa Z_{t-1}^{L}\right)^{\prime}\left(\gamma_{0}+\gamma Z_{t-1}^{G}\right)-\mu \\
u 5_{t}=\left(\kappa_{0}+\kappa Z_{t-1}^{L}\right)-\beta \\
u 6_{t}=\left(\gamma_{0}+\gamma Z_{t-1}^{G}\right)-\lambda \\
u 7_{t}=u 4_{t} u 4_{t} V R_{1}-\beta u 6_{t} u 6_{t} \beta
\end{gathered}
$$

As the model could only be estimated for the conditional $C A P M(K=1)$, $\beta$ measures the sensitivity of the bond excess returns to an international bond index and $\lambda$ is the price of risk associated with that index. $\mu$ is the 
conditional mean of the bond. $V R_{1}$ is a variance ratio that measures the proportion of the variation in the bond risk premium that is explained by variations in the prices of systematic risk.

Similarly we replace equation $(2 \mathrm{~g})$ by equation $(2 \mathrm{~h})$ :

$$
u 7_{t}=u 4_{t} u 4_{t} V R_{2}-\lambda u 5_{t} u 5_{t} \lambda
$$

and measure $V R_{2}$, the proportion of the predictable movements in bond returns that is due to time-variation in the quantities of risk.

\section{Are the Conditional Models Better Specified than Their Static Counterparts?}

A rejection of the hypotheses mentioned in section $\mathrm{A}\left(H_{01}: \gamma=0, H_{02}: \kappa\right.$ $=0$ and $H_{03}: \gamma=\kappa=0$ ) suggests that the conditional models do a good job at modeling the dynamics in the bond risk premium. However, Ghysels (1998) shows that the presence of time-varying risks and factor risk premia does not rule out the possibility that the conditional asset pricing models be misspecified. To test whether the data favor the conditional models over their static counterparts, we implement two further tests.

First, we compare, in line with Ghysels (1998), the mean squared errors (MSE) of the conditional models to those of the unconditional models. Should the data favor the conditional versions, the former should be smaller than the latter.

Second, we test whether there is any structural break in the parameters $\delta$ in (1a), $\gamma$ in (1b) and $\kappa$ in (1c) of the conditional CAPM. Taking $\delta$ as an example, we use a recursive test for structural change with unknown break point as a test of the hypothesis that $\delta$ is constant as assumed in (1a). Namely, (1a) is augmented with $G+L-2$ variables equal to the cross product of $Z_{t-1}^{G, L}$ and a dummy variable set to 1 until the breakpoint and to 0 afterwards. The "modified" system (1) (namely, (1a) augmented with the dummies, (1b) and (1c)) is estimated over the whole sample and the joint significance of the cross product of $Z_{t-1}^{G, L}$ and the dummies is tested. The procedure is repeated recursively changing the breakpoint over the sample November 1980 - February 1995. The maximum of the resulting $\chi^{2}$ statistics can be used as a test of the stability of $\delta$ in (1a). The same procedure is applied to test for the presence of a structural break in $\gamma$ in (1b) and $\kappa$ in (1c). There are however two differences. For $\gamma,(1 \mathrm{~b})$ is augmented with $G-1$ variables equal to the cross product of $Z_{t-1}^{G}$ and the dummy. For $\kappa,(1 \mathrm{c})$ is augmented with $L-$ 1 variables equal to the cross product of $Z_{t-1}^{L}$ and the dummy. 
TABLE 1. Summary Statistics

\begin{tabular}{|c|c|c|c|c|c|}
\hline & Mean & $\begin{array}{l}\text { Std. } \\
\text { Dev. }\end{array}$ & $\begin{array}{l}\text { Reward } \\
\text { to-Risk }\end{array}$ & Skewness & $\begin{array}{l}\text { Excess } \\
\text { Kurtosis }\end{array}$ \\
\hline \multicolumn{6}{|c|}{ Panel A: Bond Excess Returns } \\
\hline Australia & 0.0406 & 0.1643 & 0.25 & $-0.47 *$ & $1.44 *$ \\
\hline Belgium & 0.0336 & 0.1163 & 0.29 & $0.34 *$ & 0.53 \\
\hline Canada & 0.0313 & 0.1049 & 0.30 & 0.15 & $2.39 *$ \\
\hline France & 0.0358 & 0.1154 & 0.31 & $-0.31 *$ & $2.06^{*}$ \\
\hline Germany & 0.0197 & 0.1249 & 0.16 & 0.02 & 0.58 \\
\hline Italy & $0.0727 *$ & 0.1455 & 0.50 & -0.22 & $1.04 *$ \\
\hline Japan & 0.0397 & 0.1388 & 0.29 & $0.68 *$ & $1.79 *$ \\
\hline Netherlands & 0.0310 & 0.1217 & 0.25 & -0.04 & $0.82 *$ \\
\hline Switzerland & 0.0057 & 0.1299 & 0.04 & 0.04 & 0.19 \\
\hline UK & 0.0597 & 0.1555 & 0.38 & 0.25 & 0.26 \\
\hline US & 0.0352 & 0.1161 & 0.30 & $0.43 *$ & $1.70 *$ \\
\hline \multicolumn{6}{|c|}{ Panel B: Summary Statictics for the Risk Factors } \\
\hline Market portfolio (MKT) & $0.0828 *$ & 0.1398 & 0.59 & $-0.54 *$ & $1.75^{*}$ \\
\hline Bond portfolio (BOND) & 0.0352 & 0.1094 & 0.32 & $0.41^{*}$ & $2.19 *$ \\
\hline Exchange rate $(\mathrm{FX})$ & $0.0590 *$ & 0.1004 & 0.59 & $1.51^{*}$ & $9.81^{*}$ \\
\hline Term structure (TS) & -0.0350 & 0.0984 & -0.36 & $-1.86^{*}$ & $11.84 *$ \\
\hline Default spread (DS) & -0.0089 & 0.1007 & -0.09 & $-2.24 *$ & $19.75^{*}$ \\
\hline Unexpected inflation (UI) & -0.0192 & 0.0821 & -0.23 & $-3.64 *$ & $34.25^{*}$ \\
\hline \multicolumn{6}{|c|}{ Panel C: Pairwise Correlations in the Risk Factors } \\
\hline MKT & BOND & FX & TS & DS & UI \\
\hline MKT & & & & & \\
\hline BOND & 1 & & & & \\
\hline 0.21 & -0.13 & 1 & & & \\
\hline-0.15 & 0.10 & -0.47 & 1 & & \\
\hline 0.18 & -0.14 & 0.00 & 0.40 & 1 & \\
\hline 0.09 & 0.02 & -0.43 & 0.31 & 0.35 & 1 \\
\hline
\end{tabular}

Note: * Denotes significance at the $5 \%$ level.

\section{Data}

\section{A. International Bond Returns}

The total returns on the long-term government bonds of 11 countries were collected over the period January 1978 to February 1998 from the International Monetary Fund database (as reported by Ibbotson Associates). The bond markets considered are those of the G7 countries (Canada, France, Germany, Italy, Japan, the United Kingdom and the 
United States), Australia, Belgium, the Netherlands and Switzerland. The returns are all expressed in terms of U.S. dollars, where the risk-free rate used to calculate excess returns is the U.S. 30 day Treasury bill. Panel A of table 1 presents summary statistics for these excess returns. As expected, the bonds with the highest mean returns tend, on average, to be the most volatile. The reward-to-risk ratios show that investments in the government bonds of Italy and the U.K. offered the best risk-adjusted excess return, while the government bonds of Switzerland and Germany exhibit the worse performance. Given investors' aversion for negative skewness and positive excess kurtosis, the Australian and French government bonds seem particularly undesirable. This suggests that amodel that accommodates higher moments might be better at explaining the pricing of international government bonds (Bali and Theodossiou [2007]; Fuertes, Miffre and Tan [2005]).

\section{B. Factor Mimicking Portfolios}

We estimate constant and conditional versions of a single index model and a multifactor model. The single index model uses the world bond index as an unique benchmark. The risk factors considered in the multifactor model follow from Alder and Dumas (1983), Solnik (1974) and Elton, Gruber and Blake (1995). As detailed in the appendix, we use the following risk factors: (1) the excess return on the MSCI world equity index, (2) the excess return on SSB world government bond index, (3) a proxy for exchange rate risk and international proxies for (4) inflation, (5) the term structure of interest rates and (6) default spread.

For the static models, a Kalman filter is used to extract the unexpected components in the four latter factors. For the conditional models, mimicking portfolios for these same four factors are formed as follows (Fama and French [1993]; Chan, Karceski and Lakonishok [1998]). First the excess returns on the constituents of the Russell 2,000 index that traded continuously over the period January 1973 to February 1998 were collected. Second, the stocks' loadings on the factor that is being mimicked are estimated over a 60 month period through regressions of individual excess returns on (i) the factor unexpected component and (ii) the excess return on the Standard and Poor's composite index. Third, the stocks are ranked into five portfolios according to these loadings. In each of the subsequent 12 months, the difference in the average returns on the highest-ranked and the lowest-ranked portfolios represents the return on the factor mimicking portfolio. The procedure is then rolled forward using the most recent 60 months of data prior to the portfolio formation date. 
This procedure produces 242 estimates of the excess return on the factor mimicking portfolios. Panel B of table 1 presents summary statistics for the prices of factor risk. The annualized market risk premium equals $8.28 \%$ with a standard deviation of $14 \%$. The annualized bond risk premium equals $3.52 \%$ with a lower standard deviation $(11 \%)$. The price of $F X$ risk is positive and statistically significant at the 5\% level. The prices of risk associated with the macroeconomic factors are less important in economic and statistical terms (in spite of frequently negative skewness and positive excess kurtosis). They are also less volatile than the market portfolio. Panel $\mathrm{C}$ of table 1 reports the correlation matrix in the excess returns on the factor mimicking portfolios. These correlations are quite high for some of the interest rate related risk premia but never exceed 0.5 in absolute value. So multicollinearity is not considered to be a problem.

\section{Global and Local Instruments}

Instruments similar to Ferson and Harvey (1993) and Harvey (1995) are used. The global instruments are expected to predict the factor risk premia one period ahead. They include a constant and the first lag in: (I) the dividend yield on the MSCI world equity index, (ii) a measure of the global term structure, (iii) a proxy for the global risk of default on money market instruments, (iv) the return on the MSCI world equity portfolio and (v) the total return on the SSB world government bond.

The local instruments are used to capture the predictable change in country-specific betas. These instruments are the country specific counterparts of the global instruments. These include a constant, the lagged dividend yield on the local stock index, the lagged spread between the total returns on long and short term government securities, the lagged capital appreciation on the local stock index and the lagged total return on the local bond index. Details relating to the construction of the instruments are reported in the appendix.

\section{Empirical Results}

\section{A. Are Factor Risk Premia and Measures of Risk Time-Dependent?}

Table 2 reports, for each of the 11 bonds, $\chi^{2}$ tests of the hypotheses that the factor risk premia in (1b) and the betas in (1c) are constant $\left(H_{01}: \gamma=\right.$ 0 and $H_{02}: \kappa=0$ ). The results from the conditional CAPM and the conditional $A P T$ are reported in panels $\mathrm{A}$ and $\mathrm{B}$, respectively. 


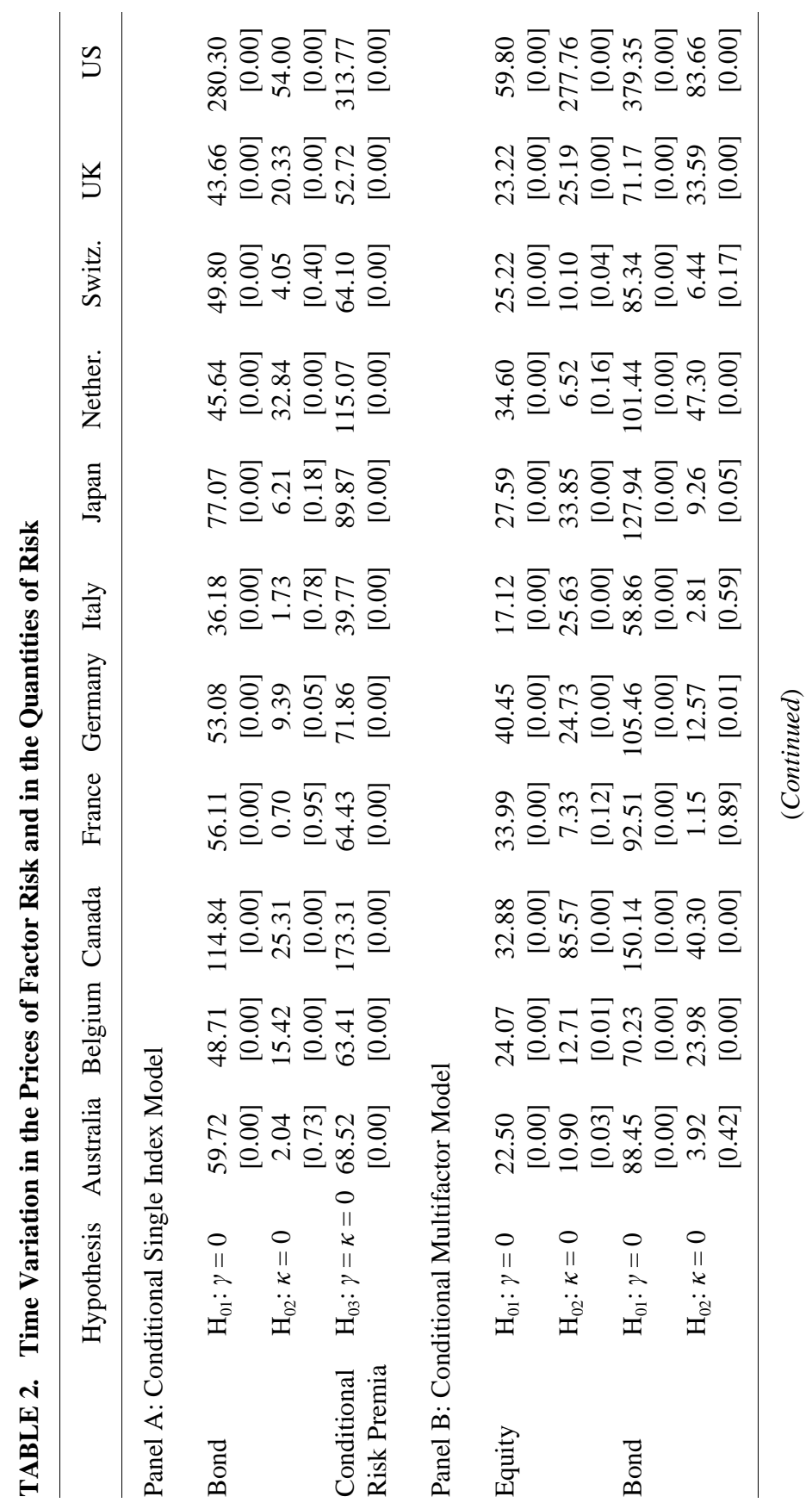


TABLE 3. Variance Ratios

\begin{tabular}{|c|c|c|c|c|}
\hline & \multicolumn{2}{|c|}{$V R_{1}$} & \multicolumn{2}{|c|}{$V R_{2}$} \\
\hline & Estimate & Std Error & Estimate & Std Error \\
\hline Australia & 0.7011 & 0.3508 & 0.0134 & 0.0211 \\
\hline Belgium & 0.9977 & 0.2143 & 0.0098 & 0.0113 \\
\hline Canada & 0.8628 & 0.0960 & 0.0035 & 0.0044 \\
\hline France & 0.5673 & 0.2128 & 0.0104 & 0.0122 \\
\hline Germany & 0.9066 & 0.1869 & 0.0048 & 0.0059 \\
\hline Italy & 0.6981 & 0.3779 & 0.0196 & 0.0269 \\
\hline Japan & 0.9644 & 0.1343 & 0.0111 & 0.0128 \\
\hline Netherlands & 0.6157 & 0.1829 & 0.0039 & 0.0052 \\
\hline Switzerland & 0.6655 & 0.1690 & 0.0034 & 0.0047 \\
\hline UK & 0.6909 & 0.1916 & 0.0079 & 0.0091 \\
\hline US & 0.9368 & 0.0523 & 0.0012 & 0.0014 \\
\hline Average & 0.7825 & & 0.0081 & \\
\hline
\end{tabular}

Note: $V R_{1}$ (and $V R_{2}$ ) are variance ratios that measure the proportions of the predictability of bond returns that are (are not) captured by the conditional CAPM.

It is clear from table 2 that these two hypotheses are repeatedly rejected at the $5 \%$ level. Both the prices of factor risk and the measures of risk are time-dependent. Irrespectively of the bond considered, the global instruments capture a change in the risk premia associated with global risk factors. There is also ample evidence to suggest that local instruments capture a change in the measures of risk at the $10 \%$ level. Interesting too is the finding that more than one risk factor explain the pricing of government bonds. This is at odds with the findings of Ilmanen (1995) who suggests that only one latent variable is needed to capture the predictability of bond returns. Our result suggests that the additional risk factors add value beyond the international bond index.

Table 2 also reports tests of the hypothesis that the betas and the factor risk premia are jointly constant $\left(H_{03}: \gamma=\kappa=0\right)$. Ultimately this is a test of the conditional multifactor model against the static model. The $\chi^{2}$ tests consistently reject, at the $1 \%$ level, the static models in favor of the conditional specifications. This suggests that the static models might be misspecified and thus may not be used for asset management, risk management and/or performance evaluation.

B. Are the Variations in the Prices of Risk More Important than the Variations in the Betas?

The estimates of $V R_{1}$ and $V R_{2}$ from system (2) are reported in table 3 for the conditional single index model (along with the standard errors in the 
TABLE 4. Mean Square Errors from Static and Conditional CAPM and APT

\begin{tabular}{llllll}
\hline & \multicolumn{2}{c}{ Static Model } & & \multicolumn{2}{c}{ Conditional Model } \\
\cline { 2 - 3 } \cline { 5 - 6 } & CAPM & APT & & CAPM & APT \\
\hline Australia & $0.214 \%$ & $0.213 \%$ & & $0.224 \%$ & $0.225 \%$ \\
Belgium & $0.101 \%$ & $0.090 \%$ & & $0.108 \%$ & $0.105 \%$ \\
Canada & $0.054 \%$ & $0.052 \%$ & & $0.088 \%$ & $0.092 \%$ \\
France & $0.101 \%$ & $0.092 \%$ & & $0.107 \%$ & $0.105 \%$ \\
Germany & $0.112 \%$ & $0.093 \%$ & & $0.125 \%$ & $0.122 \%$ \\
Italy & $0.173 \%$ & $0.169 \%$ & & $0.178 \%$ & $0.178 \%$ \\
Japan & $0.134 \%$ & $0.120 \%$ & & $0.155 \%$ & $0.150 \%$ \\
Netherlands & $0.105 \%$ & $0.091 \%$ & & $0.112 \%$ & $0.111 \%$ \\
Switzerland & $0.119 \%$ & $0.103 \%$ & & $0.135 \%$ & $0.132 \%$ \\
UK & $0.177 \%$ & $0.166 \%$ & & $0.200 \%$ & $0.193 \%$ \\
US & $0.035 \%$ & $0.029 \%$ & & $0.102 \%$ & $0.113 \%$ \\
Average & $0.120 \%$ & $0.111 \%$ & & $0.139 \%$ & $0.139 \%$ \\
\hline
\end{tabular}

Note: MSE is the mean of the squares of the difference between the bond excess returns and the bond fitted returns..

coefficient estimates). ${ }^{2}$ It is clear from the table that most of the variation in bond returns is due to variation in the price of bond risk. On average, changes in the price of risk associated with the international bond index explain $78.25 \%$ of the predictability of bond returns, while variations in betas capture less than $1 \%$ of the predictable movements in bond returns. This corroborates the evidence from the stock market of Ferson and Harvey (1993) and Braun, Nelson and Sunier (1995).

\section{Are the Conditional Models Better Specified than the Static Models?}

As Ghysels (1998) points out for the equity market, a rejection of the restrictions above (section $\mathrm{A}$ ) does not necessarily indicate that the conditional model is well specified. Bearing this point in mind, we implement the following two tests of model adequacy. First, we compare the mean squared errors (MSE) of the conditional models to that of the static models. Second, we test the restrictions that $\delta, \gamma$ and $\kappa$ are constant as assumed in (1a) - (1c). The results are reported in tables 4 and 5.

Like in Ghysels (1998), the results in table 4 indicate that the MSE of the static models are systematically smaller than those of the conditional counterparts. The evidence prevails for both the single index model and the multifactor model. The average $M S E$ of the conditional models equals

2. System (2) could not be estimated for the conditional multifactor model as the number of parameters was then prohibitively high and the model lacked degrees of freedom. 
TABLE 5. Test of Structural Stability

\begin{tabular}{|c|c|c|c|c|c|c|}
\hline & \multicolumn{2}{|c|}{$\delta$ in (1a) } & \multicolumn{2}{|c|}{$\gamma$ in (1b) } & \multicolumn{2}{|c|}{$\kappa$ in $(1 \mathrm{c})$} \\
\hline & $\chi^{2}$ & $p$-value & $\chi^{2}$ & $p$-value & $\chi^{2}$ & $p$-value \\
\hline Australia & 52.56 & 0.00 & 43.81 & 0.00 & 31.97 & 0.00 \\
\hline Belgium & 68.18 & 0.00 & 25.93 & 0.00 & 20.28 & 0.00 \\
\hline Canada & 122.67 & 0.00 & 88.33 & 0.00 & 39.33 & 0.00 \\
\hline France & 62.01 & 0.00 & 48.43 & 0.00 & 14.84 & 0.01 \\
\hline Germany & 36.87 & 0.00 & 30.74 & 0.00 & 9.16 & 0.06 \\
\hline Italy & 77.57 & 0.00 & 28.28 & 0.00 & 5.40 & 0.25 \\
\hline Japan & 65.81 & 0.00 & 65.80 & 0.00 & 21.50 & 0.00 \\
\hline Netherlands & 34.45 & 0.00 & 36.87 & 0.00 & 8.31 & 0.08 \\
\hline Switzerland & 55.05 & 0.00 & 31.99 & 0.00 & 9.19 & 0.06 \\
\hline UK & 45.90 & 0.00 & 35.56 & 0.00 & 36.16 & 0.00 \\
\hline US & 341.10 & 0.00 & 133.99 & 0.00 & 54.14 & 0.00 \\
\hline
\end{tabular}

Note: $\delta, \gamma$ and $\kappa$ measure the time-variation in the bond risk premia, the factor risk premium and the measure of risk

$0.139 \%$ for both the single and multifactor models. The average $M S E$ of the static models is $0.12 \%$ for the single index model and $0.111 \%$ for the multifactor model. This suggests that the static models do a better job at explaining the returns on international government bonds than the conditional models. As far as the static models are concerned, the MSE is slightly higher for the $C A P M$ than it is for the $A P T$, suggesting that the additional factors slightly reduce the pricing errors. This indicates once more that the additional risk factors add value beyond the international bond index.

Table 5 reports results of structural stability tests for the parameters of the conditional CAPM, where the breakpoint is unknown. The first set of columns reports $\chi^{2}$ and associated $p$-values for the null that $\delta$ in (1a) is constant. The second set of columns tests the stability of $\gamma$ in (1b), while the third focuses on $\kappa$ in (1c). The results clearly indicate a rejection of the hypothesis of constant $\delta, \gamma$ and $\kappa$ in (1a) - (1c). This suggests that, even though the conditional models seemed initially well specified (table 2), they might do more harm than good.

\section{Robustness Check}

As bonds are very sensitive to foreign exchange risk, a final check consists in testing whether our inferences are mainly driven by $F X$ movements. With this in mind, we calculate the risk premia that investors require for holding international bonds in local currencies. The results are 
reported in table 6 .

The two first columns present $\chi^{2}$ and associated $p$-values for tests of the conditional models versus their static counterparts. Clearly with $p$-values lower than $1 \%$, the data reject the static models in favor of their conditional counterparts. The variance ratios, reported in the next two columns, suggest that the conditional factor risk premium captures $61.5 \%$ of the predictable variation in bond returns, leaving $1.3 \%$ to be explaining by the conditional betas. The MSE of the static models (at $0.047 \%$ and $0.045 \%$ for the static $C A P M$ and $A P T$, respectively) are less than the MSE of the conditional models (at $0.057 \%$ and $0.059 \%$ for the conditional $C A P M$ and conditional $A P T$, respectively). Finally, the last three columns report $\chi^{2}$ and associated $p$-values from structural stability tests for $\delta$ in (1a), $\gamma$ in (1b) and $\kappa$ in (1c). The results indicate strong evidence against the hypothesis that the coefficients are constant. Clearly, currency exposure has little to no impact on the conclusions of the paper. The results are not driven by currency risk.

\section{Conclusions}

It is well known that asset returns are predictable. To get accurate estimates of the conditional risk premium of an asset, one should therefore model the time-variation in its betas and the dynamics in the risk premia associated with a set of pervasive risk factors. This statement is only valid however if the data favors the conditional model over its static counterpart. With this in mind, we estimate, for the first time, conditional and static versions of the CAPM and the APT for 11 international bond markets and, following Ghysels (1998), ask the question: Does allowing for time-varying parameters in international government bond markets help or hurt?

The paper draws the three conclusions that follow. First, we show that the conditional models are well specified. (i) Local instruments capture the change in the quantities of risk of international government bonds; (ii) global instruments can be used to model the variation in the risk premia associated with global risk factors. Second, most of the variability in international government bond returns $(78.25 \%)$ comes from changes in the price of factor risk, with the dynamics in the betas capturing less than $1 \%$ of the rational changes in bond returns. These two results extend, for the first time, the evidence of Ferson and Harvey (1993) and Harvey (1995) from international equity markets to international government bonds. Third, and following Ghysels (1998), we find that the 


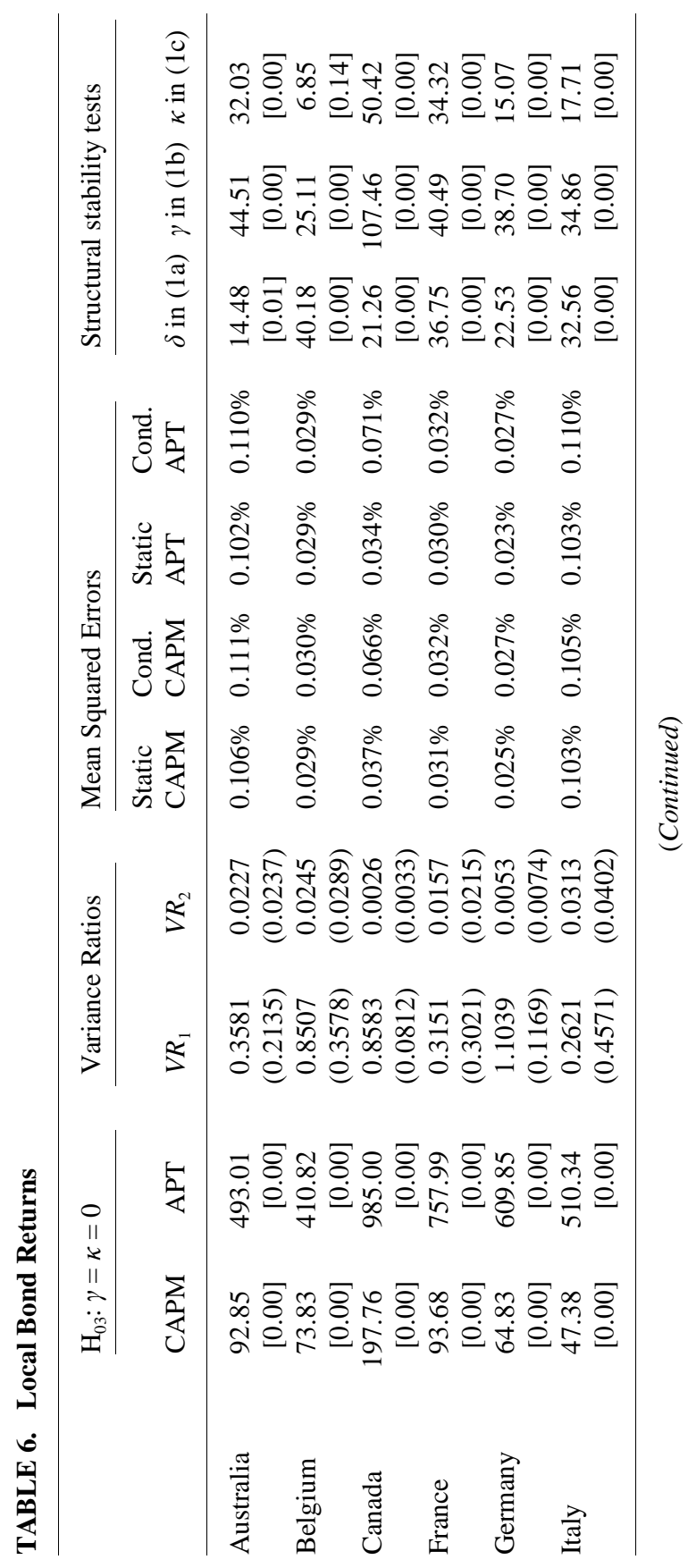




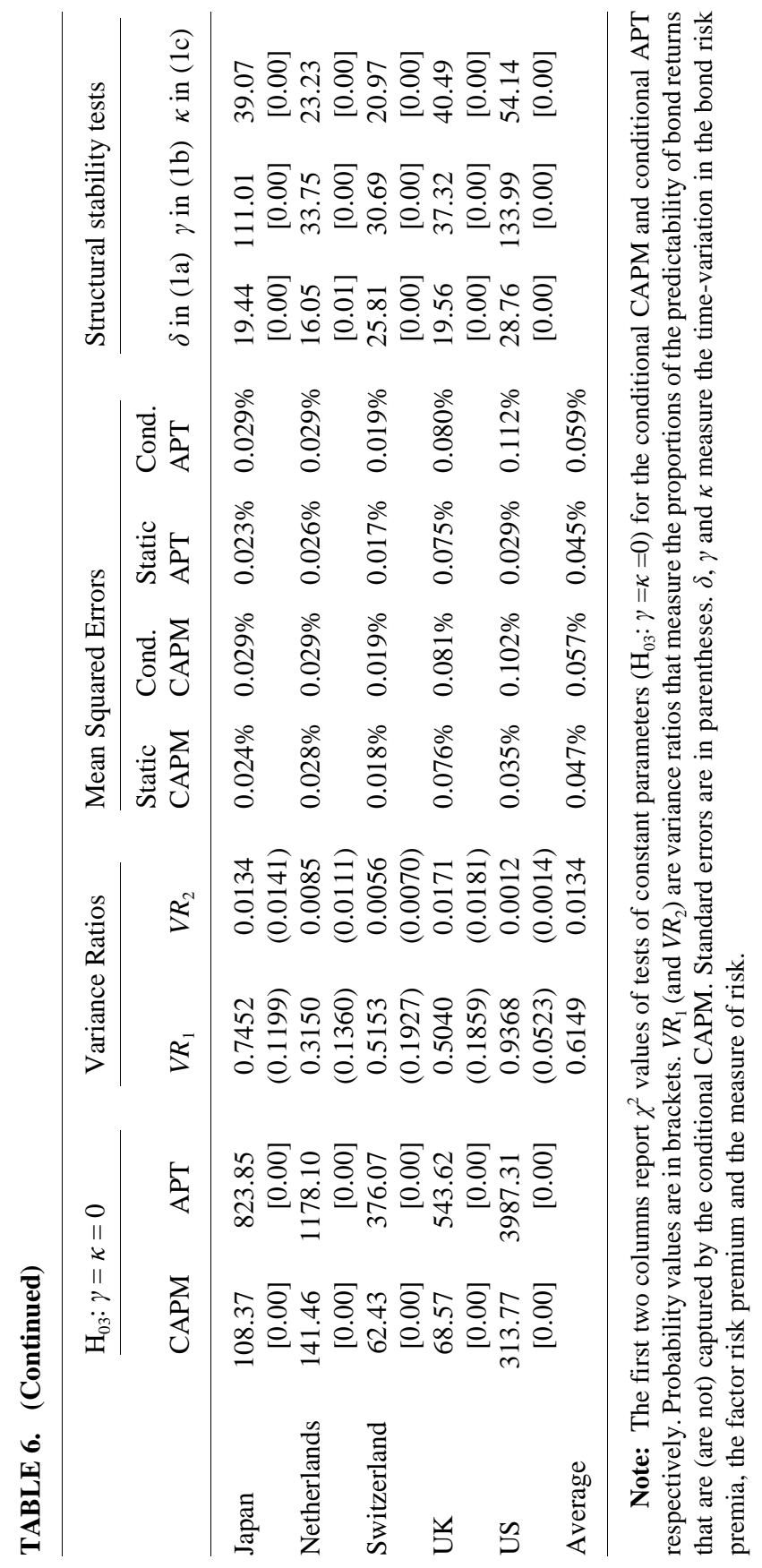


parameters of the conditional models are unstable and that the MSE of the static models are less than those of the conditional models. These tests cast doubt on the usefulness of conditional models in capturing the risk premia of international bonds, leading us to conclude with Ghysels (1998), that they might hurt more than they help. Ultimately this could explain why asset managers are still reluctant to use conditional asset pricing models for performance evaluation and risk management.

We also uncover departures from normality in the distribution of international bond returns. Ultimately, this suggests that investors should get compensation in the form of higher returns for exposure to distributions that are undesirable and that mimicking portfolios for systematic skewness and kurtosis should be included in the vector of risk factors while modeling the conditional risk premia of international bonds (Fuertes, Miffre and Tan [2005]). We leave this as a possible avenue for future research.

\section{Appendix: Data description}

The global risk factors are measured as follows. The world equity factor is defined as the U.S. dollar total return on the MSCI world equity market in excess of the U.S. 30-day Treasury bill rate. The world bond factor is defined as the U.S. dollar total return on the SSB world government bond with at least 5 years to maturity in excess of the U.S. 30-day Treasury bill rate. ${ }^{3}$ The exchange rate factor is defined as Datastream trade-weighted exchange rate expressed in U.S. dollar. Datastream percentage change in the G7 consumer price index is used for the global inflation proxy. The global term structure is measured as the difference in yields on SSB world long-term government bonds and Datastream 3-month Treasury bill discount rate. The global proxy for default spread, also called the Euro \$ spread, is estimated as the difference in the 90-day Euro\$ deposit rate and the 90-day U.S. Treasury-bill yield.

If agents are rational, all information contained in the current, past and expected values of these risk factors are already incorporated in current prices, while only the surprise in these factors is a source of priced risk. A time-varying autoregressive model is used to extract unexpected components for the $F X$ risk factor, the term spread, default spread and global inflation (see Priestley [1996], for more on this issue).

Along with a constant, the global instruments are lagged once and are as defined as follows. The world dividend yield is the income return on the MSCI world stock index. The world term structure and world default spread are measured as

3. The SSB time-series for the U.S. dollar total return on the world government bond starts in January 1985. The total return on the U.S. government bond market is used in place of the world government bond return before this date. 
above. The world stock return is the capital gain on the MSCI world stock index. The world bond return is the total return on SSB world government bonds with at least 5 years to maturity.

The local instruments include a constant and the first lag in (i) the income return on the relevant MSCI equity stock index (as a proxy for dividend yield), (ii) the local term structure, (iii) the capital appreciation on the local equity index, (iv) the total return on the local bond index.

\section{References}

Alder, M., and Dumas, B. 1983. International portfolio selection and corporation finance: A synthesis. Journal of Finance 38: 925-984.

Bali, T. G., and Theodossiou, P. 2007. A conditional-SGT-VaR approach with alternative GARCH models. Annals of Operations Research 151:241-267.

Barr, D., and Priestley, R. 2004. Expected returns, risk and the integration of international bond markets. Journal of International Money and Finance 23: 1, 71-97

Blake, C.; Elton, E.; and Gruber, M. 1993. The performance of bond mutual funds. Journal of Business 66: 3 371-403.

Braun P. A.; Nelson, D. B.; and Sunier, A. M. 1995. Good news, bad news, volatility and betas. Journal of Finance 50: 1575-1603

Campbell, J. 1987. Stock returns and the term structure. Journal of Financial Economics 18, 373-399.

Campbell, J., and Shiller R. 1988. Stock prices, earnings and expected dividends. Journal of Finance 43: 661-676

Chan, L.; Karceski, J.; and Lakonishok, J. 1998. The risk and return from factors. Journal of Financial and Quantitative Analysis 33: 159-188.

Chang, E., and Huang, R. 1990. Time-varying return and risk in the corporate bond market. Journal of Financial and Quantitative Analysis 25(3): 323340 .

Demos, A., and Parissi, S. 1998. Testing asset pricing models: The case of Athens stock exchange. Multinational Finance Journal 2(3): 189-223.

Detzler, M. 1999. The performance of global bond mutual funds. Journal of Banking and Finance 23(8): 1195-1217.

Elton, E.; Gruber, M.; and Blake, C. 1995. Fundamental economic variables, expected returns and bond fund performance. Journal of Finance 50(4): 1229-1256.

Fama, E. F. 1991. Efficient capital markets: II. Journal of Finance 46: 15751617.

Fama, E., and French, K. 1988. Dividend yields and expected stock returns. Journal of Financial Economics 22, 1: 3-25.

Fama, E.. and French, K. 1989. Business conditions and expected returns on stocks and bonds. Journal of Financial Economics 25(1): 23-49.

Fama, E. F., and French, K. R. 1993. Common risk factors in the returns on 
stocks and bonds. Journal of Financial Economics 25: 3-56.

Ferson, W. E., and Harvey, C. R. 1993. The risk and predictability of international equity returns. Review of Financial Studies 6: 527-566.

Ferson, W. E., and Korajczyk, R. A. 1995. Do arbitrage pricing models explain the predictability of stock returns? Journal of Business 68(3): 309-349.

Fuertes, A-M.; Miffre J; and Tan, W-H., 2005, Momentum profits and non-normality risks, Working paper, Cass Business School.

Ghysels, E. 1998. In stable factor structures in the pricing of risk: Do time-varying betas help or hurt? Journal of Finance 53(2): 549-573.

Harvey, C. 1995. Predictable risk and returns in emerging markets. Review of Financial Studies 8: 773-816.

Ilmanen, A. 1995. Time-varying expected returns in international bond markets. Journal of Finance 50: 481-506.

Miffre, J. 2000. Normal backwardation is normal. Journal of Futures Markets 20(9): 803-821.

Priestley, R. 1996. The APT, macroeconomic and financial factors and expectations generating processes. Journal of Banking and Finance 20(5): $869-890$.

Solnik, B. 1974. An equilibrium model of the international capital market. Journal of Economic Theory 8: 500-524.

Zhang, X. 2004, Specification tests of international asset pricing models, Journal of International Money and Finance, forthcoming.. 